\title{
PESQUISA-AÇÃO, OBSERVAÇÃO PARTICIPANTE E A EXTENSAO RURAL
}

\author{
Maria Helena Rocha Antuniassi ${ }^{1}$
}

\section{Resumo:}

$\mathrm{O}$ artigo expõe algumas reflexões sobre a metodologia da pesquisa-ação, na modalidade observação participante, realizadas no CERU/NAP/USP, a partir de um estudo de sociologia, desenvolvido no âmbito de um programa de extensão rural realizado no Vale do Ribeira/SP, juntamente com o Prof. Dr. Luís Carlos Ferreira de Almeida do curso de agronomia da UNESP - Universidade Estadual Paulista Campus Experimental de Registro.

Palavras-chave: Pesquisa-acão. Observação participante. Extensão rural. Vale do Ribeira.

\section{ACTION-RESEARCH, PARTICIPANT OBSERVATION AND RURAL EXTENSION}

\begin{abstract}
This article aims to expose some reflections on the methodology of action research, in the participant observation modality, carried out from a sociological study, developed within the scope of a rural extension program in Vale do Ribeira/SP, together with the Prof. Dr. Luis Carlos Ferreira de Almeida from the Agronomy Faculty at UNESP - São Paulo State University Experimental Campus of Registro (State of São Paulo).
\end{abstract}

Keywords: Action research. Participant observation. Rural extension. Vale do Ribeira.

Este artigo tem o objetivo de expor algumas reflexões sobre a metodologia da pesquisaação, na modalidade observação participante, realizadas com base em um estudo de sociologia, ${ }^{2}$ desenvolvido no âmbito de um programa de extensão rural no Vale do Ribeira/SP, juntamente com o Prof. Dr. Luís Carlos Ferreira de Almeida do curso de agronomia da UNESP Universidade Estadual Paulista Campus Experimental de Registro e uma equipe de estudantes ${ }^{3}$

O citado estudo teve como objetivo disseminar junto aos produtores rurais, sobretudo da agricultura familiar, conceitos e práticas relativas à saúde do trabalhador, principalmente, a correta utilização do EPI (equipamento de proteção individual) e preservação do meio ambiente (solo e águas) para que suas atividades se efetivem direcionadas para o desenvolvimento sustentado (socioeconômico e ambiental) de seu município e região.

Fundamentamo-nos no pressuposto de que a utilização da pesquisa-ação/observação participante como metodologia de pesquisa qualitativa empírica, possibilita que a análise de determinadas ações de um grupo social gere conhecimentos que permitam criar estratégias de transformação das mesmas, e, consequentemente, da dinâmica de uma determinada situação social vivenciada por esse grupo. Considera-se, portanto, que a pesquisa- ação na modalidade de observação participante objetiva compreender e intervir. Intervenção por meio de ação

\footnotetext{
${ }^{1}$ Pesquisadora, membro da diretoria do CERU (Centro de Estudos Rurais e Urbanos - CERU/NAP/USP). E-mail: mhrochaa@gmail.com.

${ }^{2}$ Representação e práticas de utilização de produtos agroquímicos na pequena agricultura familiar do Vale do Ribeira Estado de São Paulo- Brasil. Cadernos CERU, v. 26, n. 2, dez. 2015.

3 Daniele da Silva, Leonardo dos Santos Duarte, Lorenzo Gomes Mascetra e Davenil Augusto Magri.
} 
pedagógica, tendo por base não apenas o conhecimento adquirido sobre a vivência dos agentes observados, mas também das condições de possibilidade de transformação dessa vivência.

O conhecimento adquirido pela observação está constantemente em relação dialética com a prática. Se na realização de uma pesquisa de investigação o pesquisador observa o grupo social, colocando-se fora dele para descrever e analisar, na metodologia da observação participante, o pesquisador deve se integrar no grupo, tornar-se participante para observá-lo de seu interior (DIAZ, 2005) . É preciso compreender a posição, as representações e ações de cada grupo social na estrutura e dinâmica da situação social observada, isto é, compreender a significação e complexidade do social produzido na interação dos atores considerados.

No contexto da metodologia, na observação participante pesquisadores e grupos em observação tornam-se parceiros, o que pressupõe o contato direto entre os atores (no caso pesquisadores, técnicos, estudantes e agricultores). Esse contato é que vai permitir o estudo objetivo da inter-relação entre os atores e suas implicações nas ações sociais de cada grupo, e seu posicionamento no processo social. Nesse contexto, são abertas oportunidades, inclusive, para observação e análise das práticas objetivas, no nosso estudo as práticas de cultivo desenvolvidas pelo grupo de agricultores.

Nessas circunstâncias, torna-se relevante considerar o conhecimento prévio do pesquisador sobre os grupos participantes (seja adquirido pelo estudo ou pela vivência) principalmente sobre sua história e características regionais de seu habitat, dados relevantes para situar os grupos na sociedade mais ampla, conhecimentos esses implicados nas relações intergrupos e na aceitação do pesquisador pelos mesmos.

Um exemplo de pesquisa-ação, no sentido mencionado, é a experiência vivenciada com os professores de uma escola, que foram conduzidos a negociar as "Leis da classe" com seus alunos, o que criou condições para uma melhor aprendizagem. Foram estudados os efeitos de uma avaliação competitiva e numérica que depois foi substituída por uma avaliação descritiva com o objetivo de chegar a uma auto avaliação (LAPASSADE, 1993, s.p., tradução nossa).

A história da pesquisa-ação, desde sua concepção, associada a Kurt Levin apresenta um período de ampla utilização nas décadas de 40 a 60, entrando, em seguida, em uma fase de declínio nos anos 70. Nos anos 80 ressurgem enfatizando e ampliando o agir, isto é, a ação (LAPASSADE, 1993), sobretudo nas pesquisas educacionais.

No Brasil, a metodologia da pesquisa-ação tem sido bastante utilizada nas pesquisas sócio- antropológicas, a partir dos anos 90, inspiradas na obra pioneira de Thiollent cujo livro "Metodologia da Pesquisa Ação" conceitua essa metodologia como

um tipo de pesquisa social com base empírica que é concebida e realizada em estreita associação com urna ação ou com a resolução de um problema coletivo e no qual os pesquisadores e os participantes representativos da situação ou do problema estão envolvidos de modo cooperativo ou participativo (THIOLLENT, 1986, p. XX).

Na modalidade observação-participante, a que se refere este artigo, a participação do pesquisador na pesquisa-ação não se restringe à análise do fato social. O seu agir, ampliado, desenvolve-se na direção da mudança social como parte intrínseca do objetivo da pesquisa. A 
proposta é que o cientista social, ao desenvolver uma pesquisa-ação, pode e deve colocar as ciências sociais a serviço de uma bem planejada mudança social.

Na pesquisa que deu origem a este artigo, buscou-se apreender a representação dos agricultores sobre os produtos agroquímicos, suas práticas de utilização e desenvolver ações pedagógicas para modificá-las ou aperfeiçoá-las.

Tendo em vista os objetivos fixados, a pesquisa em questão envolveu três grupos além dos pesquisadores: o grupo de técnicos-agrônomos das Casas de Agricultura e/ou funcionários da prefeitura municipal, o grupo de estudantes de Agronomia e o grupo de pequenos agricultores ligados à agricultura familiar da região. A pesquisa foi desenvolvida da seguinte forma:

1 - Revisão bibliográfica sobre a metodologia a ser utilizada, sobretudo produzida na Sociologia e Antropologia;

2 - Escolha da região, com uma significativa população de pequenos agricultores familiares, cujo cultivo inclui a utilização de agroquímicos, com indícios de falta de conhecimentos sobre as características e consequências dessa utilização;

3 - Eleição e colocação em prática de estratégias facilitadoras para observação e, se necessário, promoção de inter-relações e entrosamento dos grupos (técnicos e agricultores) na região, tendo em vista captar a dinâmica do relacionamento entre esses grupos (primeira fase do trabalho de campo);

4- Organização de reuniões entre os grupos nas quais, cada um exercendo seu papel, promovesse a obtenção, diretamente com os agricultores, de informações sobre suas práticas de utilização dos produtos agroquímicos, e em seguida, informá-los da necessidade de ajustes e correções dessas práticas tendo em vista a consecução dos objetivos estabelecidos no projeto de pesquisa.

\section{Desenvolvimento da Pesquisa}

Considerando o planejamento traçado, as primeiras tarefas executadas dizem respeito a revisão bibliográfica:

a) Sobre a metodologia a ser colocada em pratica, realizada pelos professores, pesquisadores e discussão com o grupo de estudantes (ANTUNIASSI, M.H.R; ALMEIDA, L.C.F.).

b) Sobre a agricultura familiar no Estado de São Paulo (realizada pelos professores e alunos) tendo em vista selecionar uma região com predominância desse tipo de agricultura, com evidências de forte utilização de agroquímicos, IDH abaixo da média estadual, supondo uma população com baixo nível de escolarização e, portanto, grande possibilidade de desconhecimento de conceitos e práticas relativas à saúde do trabalhador, sobretudo a necessidade de correta utilização do EPI, assim como corretas práticas de transporte, armazenamento e descarte de embalagens tendo em vista a preservação do meio ambiente (águas e solos).

O levantamento bibliográfico estendeu-se inclusive aos jornais de maior circulação no Estado de São Paulo (Folha de São Paulo e Estado de São Paulo), considerando a existência de reportagens tendo em vista graves problemas na organização do trabalho, como não utilização de equipamentos de segurança adequados para a utilização de agroquímicos, com o agravante 
da presença de trabalhadores menores de idade (Irregularidades constatadas pela fiscalização da DRT e do Ministério Público do Trabalho).

Após a referida análise bibliográfica, levando em consideração as características acima mencionadas, foi escolhida para realização do trabalho de campo, a região da Bacia Hidrográfica do Rio Ribeira do Iguape e o Complexo Estuário Lacunar de Iguape-CananeiaParanaguá, conhecida como Vale do Ribeira, que abrange as regiões sudeste do Estado de São Paulo e leste do Estado do Paraná.

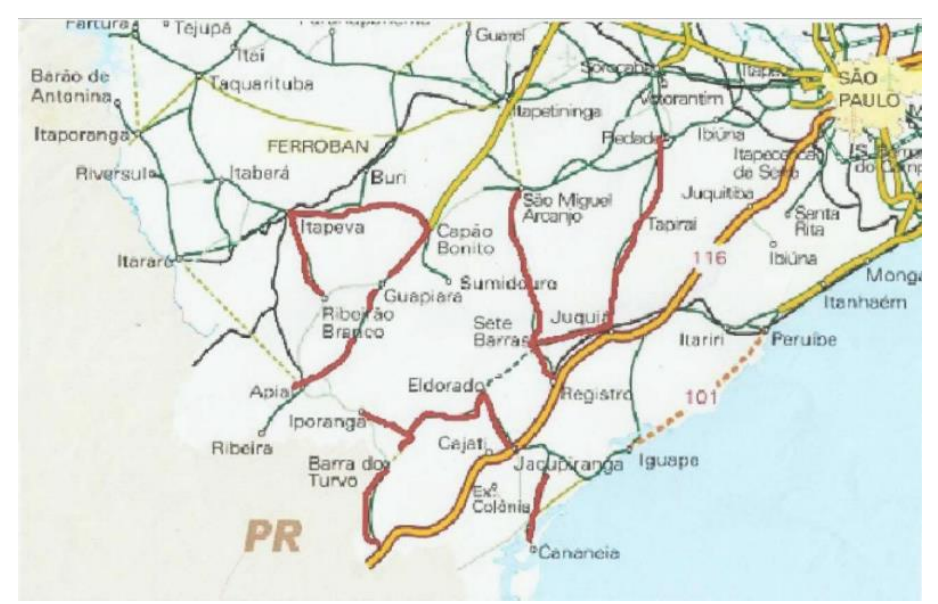

Figura 1 - Região do Vale do Ribeira

Essa região abrange um total de trinta e um municípios (vinte e dois no Estado de São Paulo e nove no Estado do Paraná) uma população de cerca de 484.412 habitantes, com $50 \%$ localizando-se em zona definida como rural pelo IBGE. Grande parte desses municípios apresenta os menores índices IDH (Índice de Desenvolvimento Humano) no Estado de São Paulo com altos índices de analfabetismo, mortalidade infantil, condições precárias de habitação, falta de infraestrutura de saneamento básico.

Em seguida foi iniciada a primeira etapa do trabalho de campo, o contato com o pessoal da CATI (Coordenadoria de Assistência Técnica Integral/Secretaria da Agricultura) que nos auxiliou na escolha dos municípios para a segunda fase do trabalho de campo.

Os seguintes municípios foram selecionados: Registro, Apiaí, Cananeia, Capão Bonito, Guapeara, Itapeva, Jacupiranga, Pilar do Sul, Ribeirão Branco e São Miguel Arcanjo, todos perfeitamente enquadrados nos parâmetros colocados no contexto da pesquisa: taxa de urbanização inferior à média do Estado de São Paulo e expressiva participação da agricultura no total dos empregos formais e do setor agropecuário na economia. Um fator que contribui para esse fato diz respeito ao tipo de agricultura praticada, voltada sobretudo para produtos com baixa capacidade de transformação implicando baixos rendimentos: agricultura de subsistência, olericultura e cultura da uva, produtos cultivados por pequenos agricultores com utilização de mão de obra familiar e utilização de produtos agroquímicos.

\section{Estratégias de desenvolvimento da Pesquisa-ação}

No desenrolar da pesquisa foram desenvolvidas algumas atividades estratégicas para reunião dos grupos envolvidos na pesquisa, como reuniões sociais, palestras, demonstração de 
utilização de equipamentos, e aplicação de questionários. Em cada um dos municípios os agricultores foram recrutados pelo grupo de técnicos da secretaria de agricultura para participação nas atividades programadas e as estratégias foram as mesmas, em um primeiro momento: os grupos de agrônomos e técnicos agrícolas, estudantes e agricultores eram convidados para uma reunião social, um almoço informal em que pesquisadores e estudantes tiveram oportunidade de conversar livremente com agricultores e técnicos (agrônomos e técnicos agrícolas) do município e os pesquisadores tiveram condições de observar o suposto entrosamento entre técnicos e agricultores.

Em um segundo momento, os grupos foram convidados para uma palestra sobre a utilização de agroquímicos. Antes da palestra técnicos e agricultores foram incentivados a responder a um questionário com quinze questões fechadas (certo, errado e não sei) tendo em vista avaliar o conhecimento dos agricultores sobre os agroquímicos e sua utilização. Imediatamente depois, os pesquisadores fizeram uma palestra versando sobre a correta utilização dos agroquímicos e os estudantes uma demonstração da utilização do EPI. Em seguida os agricultores foram convidados a responder um segundo questionário com questões semelhantes apresentadas no primeiro questionário

Os resultados dos questionários foram tabulados quanto ao número de acertos/erros levando em consideração as variáveis: município da pesquisa, sexo, idade e nível de instrução. Devido à metodologia utilizada foram considerados somente os questionários cujos respondentes participaram ANTES e DEPOIS da palestra e demonstração, totalizando 123 questionários.

\section{Tabela 1 -}

Distribuição dos respondentes por cidade ${ }^{4}$

\begin{tabular}{|c|c|c|}
\hline Municipal & $\begin{array}{c}\text { Frequência } \\
\text { Absoluta }\end{array}$ & $\begin{array}{c}\text { Frequência } \\
\text { Relativa (\%) }\end{array}$ \\
\hline Apiaí & 10 & 8,1 \\
\hline Cananéia & 19 & 15,4 \\
\hline Capão Bonito & 16 & 13,0 \\
\hline Guapiara & 9 & 7,3 \\
\hline Itapeva & 25 & 20,3 \\
\hline Jacupiranga & 10 & 8,1 \\
\hline Pilar do Sul & 27 & 22,0 \\
\hline Ribeirão Branco & 7 & 5,7 \\
\hline Total & 123 & 100,0 \\
\hline
\end{tabular}

Quanto aos resultados obtidos, tendo em vista os objetivos da pesquisa, é importante ressaltar que: em relação à variável sexo, o público participante foi majoritariamente masculino, em uma proporção de 3 para 1 . Os dados relativos à idade e escolaridade apresentaram grande dispersão, de um ano de escola formal a nível universitário e idades entre dezoito e oitenta anos.

\footnotetext{
${ }^{4}$ Não foram considerados os respondentes da cidade de Registro, onde foi realizado o treinamento dos estudantes.
} 
Cadernos CERU, Série 2, Vol. 32, n. 1, jun. 2021 
Tabela 2 - Momento ANTES

\begin{tabular}{|c|c|c|c|c|c|c|c|c|}
\hline \multirow[t]{2}{*}{ Questões } & \multicolumn{2}{|c|}{ Respostas Erradas } & \multicolumn{2}{|c|}{ Respostas Certas } & \multicolumn{2}{|c|}{ Não Sei } & \multicolumn{2}{|c|}{ Total } \\
\hline & $\mathbf{N}$ & $\%$ & $\mathbf{N}$ & $\%$ & $\mathbf{N}$ & $\%$ & $\mathbf{N}$ & $\%$ \\
\hline $\begin{array}{l}\text { 1) Exposição a uma grande quantidade de } \\
\text { agrotóxicos em curto espaço de tempocausa } \\
\text { intoxicação }\end{array}$ & 33 & 26,8 & 35 & 28,5 & 55 & 44,7 & 123 & 100,0 \\
\hline $\begin{array}{l}\text { 2) Exposição em pequenas quantidades de } \\
\text { agrotóxicos em um longo espaço de tempo } \\
\text { causa intoxicação }\end{array}$ & 28 & 22,8 & 45 & 36,6 & 50 & 40,7 & 123 & 100,0 \\
\hline $\begin{array}{l}\text { 3) Se o aplicador está de luvas, ele pode } \\
\text { fumar entre as aplicações de agrotóxicos }\end{array}$ & 8 & 6,6 & 114 & 93,4 & - & - & 122 & 100,0 \\
\hline $\begin{array}{l}\text { 4) Um agrotóxico "fraco" pode ser } \\
\text { perigoso mesmo em pequenas quantidades? }\end{array}$ & 4 & 3,3 & 117 & 96,7 & - & - & 121 & 100,0 \\
\hline $\begin{array}{l}\text { 5) Período de carência é o tempo entre a } \\
\text { pulverização e a colheita }\end{array}$ & 39 & 33,3 & 78 & 66,7 & - & - & 117 & 100,0 \\
\hline $\begin{array}{l}\text { 6) Uma área foi pulverizada e o agricultor } \\
\text { esqueceu uma ferramenta no meio da } \\
\text { cultura; ele pode entrar para procurar no } \\
\text { final do dia? }\end{array}$ & 39 & 32,8 & 80 & 67,2 & - & - & 119 & 100,0 \\
\hline $\begin{array}{l}\text { 7) Você veio à cidade de caminhonete e } \\
\text { comprou adubos, ração e agrotóxicos, esses } \\
\text { produtos podem ir na caçamba? }\end{array}$ & 26 & 21,1 & 97 & 78,9 & - & - & 123 & 100,0 \\
\hline $\begin{array}{l}\text { 8) Você veio à cidade de caminhonetee } \\
\text { comprou adubos, ração e agrotóxicos. } \\
\text { Somente o agrotóxico pode ir na cabine } \\
\text { para não misturar com a ração. }\end{array}$ & 25 & 20,5 & 97 & 79,5 & - & - & 122 & 100,0 \\
\hline $\begin{array}{l}\text { 9) Desde que bem fechado e lacrado, um } \\
\text { agrotóxico pode ser guardado dentro de } \\
\text { casa, desde que o local seja seguro e } \\
\text { fechado a chave. }\end{array}$ & 19 & 15,7 & 102 & 84,3 & - & - & 121 & 100,0 \\
\hline $\begin{array}{l}\text { 10) Ao usar o EPI, a bota deve ficar para } \\
\text { fora da calça }\end{array}$ & 75 & 62,5 & 45 & 37,5 & - & - & 120 & 100,0 \\
\hline $\begin{array}{l}\text { 11) Ao pulverizar uma cultura com a mão } \\
\text { para cima a luva tem que ficar }\end{array}$ & 30 & 24,8 & 91 & 75,2 & - & - & 121 & 100,0 \\
\hline $\begin{array}{l}\text { 12) Ao pulverizar uma cultura com a mão } \\
\text { para baixo a luva tem que ficar }\end{array}$ & 47 & 39,2 & 73 & 60,8 & - & - & 120 & 100,0 \\
\hline $\begin{array}{l}\text { 13) As embalagens vazias de agrotóxicos, } \\
\text { para evitar contaminação, devem ser } \\
\text { enterradas em um local seguro }\end{array}$ & 42 & 35,0 & 78 & 65,0 & - & - & 120 & 100,0 \\
\hline $\begin{array}{l}\text { 14) } \mathrm{Na} \text { hora de aplicar o agrotóxico, o } \\
\text { aplicador deve ficar }\end{array}$ & 51 & 42,5 & 69 & 57,5 & - & - & 120 & 100,0 \\
\hline $\begin{array}{l}\text { 15) Dias quentes e bem secos são bons } \\
\text { para aplicar o agrotóxico }\end{array}$ & 32 & 26,7 & 88 & 73,3 & - & - & 120 & 100,0 \\
\hline
\end{tabular}


Tabela 3 - Momento DEPOIS

Em relação às perguntas do questionário relativas às questões básicas da utilização dos

\begin{tabular}{|c|c|c|c|c|c|c|c|c|}
\hline \multirow[t]{2}{*}{ Questões } & \multicolumn{2}{|c|}{ Respostas Erradas } & \multicolumn{2}{|c|}{ Respostas Certas } & \multicolumn{2}{|c|}{ Não Sei } & \multicolumn{2}{|c|}{ Total } \\
\hline & $\mathbf{N}$ & $\%$ & $\mathbf{N}$ & $\%$ & $\mathbf{N}$ & $\%$ & $\mathbf{N}$ & $\%$ \\
\hline $\begin{array}{l}\text { 1) Exposição a uma grande quantidade } \\
\text { de agrotóxicos em curto espaço de } \\
\text { tempo causa intoxicação }\end{array}$ & 19 & 15,4 & 98 & 79,7 & 6 & 4,9 & 123 & 100,0 \\
\hline $\begin{array}{l}\text { 2) Exposição em pequenas quantidades } \\
\text { de agrotóxicos em um longo espaço de } \\
\text { tempo causa intoxicação }\end{array}$ & 15 & 12,2 & 101 & 82,1 & 7 & 5,7 & 123 & 100,0 \\
\hline $\begin{array}{l}\text { 3) Se o aplicador está de luvas, ele pode } \\
\text { fumar entre as aplicações de } \\
\text { agrotóxicos }\end{array}$ & 1 & 0,8 & 122 & 99,2 & - & - & 123 & 100,0 \\
\hline $\begin{array}{l}\text { 4) Um agrotóxico "fraco" pode ser } \\
\text { perigoso, mesmo em } \\
\text { quantidades? }\end{array}$ & 5 & 4,1 & 118 & 95,9 & - & - & 123 & 100,0 \\
\hline $\begin{array}{l}\text { 5) Período de carência é o tempoentre } \\
\text { a pulverização e a colheita }\end{array}$ & 25 & 20,7 & 96 & 79,3 & - & - & 121 & 100,0 \\
\hline $\begin{array}{l}\text { 6) Uma área foi pulverizada e o } \\
\text { agricultor esqueceu uma ferramentano } \\
\text { meio da cultura; ele pode entrar para } \\
\text { procurar no final do dia? }\end{array}$ & 10 & 8,4 & 109 & 91,6 & - & - & 119 & 100,0 \\
\hline $\begin{array}{l}\text { 7) Você veio à cidade de caminhonete } \\
\text { e comprou adubos, ração e agrotóxicos, } \\
\text { esses produtos podem ir na caçamba? }\end{array}$ & 24 & 19,5 & 99 & 80,5 & - & - & 123 & 100,0 \\
\hline $\begin{array}{l}\text { 8) Você veio à cidade de caminho- nete } \\
\text { e comprou adubos, ração e agrotóxicos. } \\
\text { Somente o agrotóxico pode ir na cabine } \\
\text { para não misturarcom a ração. }\end{array}$ & 10 & 8,2 & 112 & 91,8 & - & - & 122 & 100,0 \\
\hline $\begin{array}{l}\text { 9) Desde que bem fechado e lacra- do, } \\
\text { um agrotóxico pode ser guarda- do } \\
\text { dentro de casa, desde que o localseja } \\
\text { seguro e fechado a chave. }\end{array}$ & 8 & 6,6 & 114 & 93,4 & - & - & 122 & 100,0 \\
\hline $\begin{array}{l}\text { 10) Ao usar o EPI, a bota deve ficarpara } \\
\text { fora da calça }\end{array}$ & 87 & 71,3 & 35 & 28,7 & - & - & 122 & 100,0 \\
\hline $\begin{array}{l}\text { 11) Ao pulverizar uma cultura coma } \\
\text { mão para cima a luva tem que ficar }\end{array}$ & 20 & 16,7 & 100 & 83,3 & - & - & 120 & 100,0 \\
\hline $\begin{array}{l}\text { 12) Ao pulverizar uma cultura coma } \\
\text { mão para baixo a luva tem que ficar }\end{array}$ & 17 & 14,3 & 102 & 85,7 & - & - & 119 & 100,0 \\
\hline $\begin{array}{l}\text { 13) As embalagens vazias de agro- } \\
\text { tóxicos, para evitar contaminação, } \\
\text { devem ser enterradas em um local } \\
\text { seguro }\end{array}$ & 20 & 16,3 & 103 & 83,7 & - & - & 123 & 100,0 \\
\hline $\begin{array}{l}\text { 14) Na hora de aplicar o agrotóxicoo } \\
\text { aplicador deve ficar }\end{array}$ & 31 & 25,4 & 91 & 74,6 & - & - & 122 & 100,0 \\
\hline $\begin{array}{l}\text { 15) Dias quentes e bem secos sãobons } \\
\text { para aplicar o agrotóxico }\end{array}$ & 15 & 12,3 & 107 & 87,7 & - & - & 122 & 100,0 \\
\hline
\end{tabular}

agroquímicos, nenhum dos respondentes acertou todas as questões, o que já nos esclareceu que 
nem todas as informações sobre o uso correto de agroquímicos estavam disseminadas entre os agricultores.

Considerando as respostas dos questionários ANTES e DEPOIS, constatou-se que no momento DEPOIS, ocorre uma sensível redução de questões com resultados errados e da alternativa "não sei” o que demonstrou que a didática apresentada contribuiu para o aprendizado dos participantes. Entre o questionário ANTES E DEPOIS foi significativa a alteração no total de acertos. No ANTES, apenas vinte e sete participantes acertaram a maior parte das questões, enquanto no momento depois, o total sobe para setenta e seis.

Para verificar a existência de possíveis relações entre acertos e erros análises estatísticas mais especificas foram realizadas, por exemplo:

- com relação à idade, os resultados mostraram uma relação inversa: quanto mais velho o respondente, menor o número de acertos;

- com relação à variável sexo, os dados não mostraram relação significativa;

- resumindo, o importante é esclarecer que a diferença das médias para todas as questões, entre os dois momentos (ANTES e DEPOIS) foram significativas; isto é, o nível de acertos melhorou, significativamente, após a apresentação das palestras e demonstrações.

Assim sendo, a análise dos dados permitiu concluir que os resultados das atividades do palestrante e da demonstração realizada pelos estudantes foram positivos. No contexto das atividades de aplicação dos questionários, pode-se observar que os agricultores conheciam uma parte das questões formuladas, entretanto, ficou claro que o conjunto das normas de segurança na utilização de agroquímicos é desconhecido de significativo percentual da população de agricultores, sobretudo:

1- o rigor na utilização do EPI;

2 - armazenamento do produto e

3 - período de carência na aplicação, assim como pontos relativos à diferenciação entre situações que podem levar à intoxicação crônica e aguda.

No contexto das atividades, foi possível ainda observar que se torna necessário um estreitamento das relações entre agrônomos e técnicos extensionistas com os pequenos agricultores e suas associações para revitalizá-las e, assim, contribuir para maior efetividade de suas ações, no que se refere ao papel da agricultura familiar no desenvolvimento agrícola e consequentemente da sócio-economia regional.

No estudo «Evolução do processo de formação, organização e atuação das associações de pequenos produtores rurais » foi possível verificar que a estabilidade e o sucesso das associações, em especial as cooperativas, estão fortemente ligados a capacidade de gerenciar e criar recursos, e a presença constante do agrônomo extensionista é fator fundamental no desenvolvimento dessas atividades (ANTUNIASSI, 2009, p. 20).

Em resumo, pode-se dizer que o trabalho de observação sociológica e pedagógico permitiu atingir os objetivos propostos e levantar uma série de hipóteses explicativas a serem retomadas em futuros estudos.

Assim sendo, a metodologia da pesquisa-ação na modalidade observação participante, considerando as estratégias utilizadas, respondeu satisfatoriamente, permitindo a obtenção dos resultados esperados. 
Finalizamos o presente artigo, defendendo a hipótese de que a metodologia pesquisaação, observação participante, constitui um processo democrático em que pesquisadores, técnicos e grupos sociais observados é altamente apropriada para compreender e agir tendo em vista situações sociais, um campo, conforme Bourdieu, ${ }^{5}$ como as comunidades rurais que buscam o auxílio dos diferentes atores da extensão rural (sociólogos, antropólogos, agrônomos, técnicos agrícolas e outros) diante de problemas colocados no desenrolar do vivenciado processo social.

Gostaria ainda de ressaltar que, considerando os princípios gerais da metodologia da pesquisa-ação na modalidade observação-participante, uma serie de observações relativas ao aproveitamento dos estudantes, no curso de extensão rural (graduação e pós-graduação) que me leva a recomendar a utilização da metodologia em questão, tendo em vista que a mesma proporciona uma vivência dos estudantes com a população alvo, no caso, produtores rurais, que antecipa situações a serem vivenciadas no decorrer do exercício da profissão, que pode leválos a repensar dilemas desse relacionamento, como estereótipos, por exemplo, facilitando o diálogo como profissional e cidadão/cidadã.

Considerando a noção de historicidade e de mutabilidade da realidade social intrínseca à metodologia em questão, é preciso ressaltar a importância que a extensão rural tende a assumir neste momento, tendo em vista os problemas ambientais que precisam e devem ser discutidos, questionados e solucionado em nossa sociedade pela população rural, vilã e vítima desse processo, como a destruição de florestas, o negligenciamento das matas ciliares e consequentemente dos cursos dos rios.

\section{Bibliografia}

ACCARDO, A. Initiation à la sociologie - L'illusionnisme social, une lecture de Bourdieu. Bordeaux: Le Mascaret, 1983.

ANADON, M. (Org.) La rechercche participative: Multiple Regards. Quebec: Presses de l'Université du Quebec, 2008.

ANTUNIASSI, M.H.R. Evolução do processo de formação, organização e atuação das associações de pequenos produtores rurais. Impresso Especial CATI: Campinas, 2009.

BOURDIEU, P. L'objetivation participante. Actes de la recherche en sciences sociales, 150, Paris, p 43-58, 2003.

DIAZ, F. L'observation comme outil de compréhension de champ de la sécurité. Champ pénal/Penal field, Vol. II, 2005. Disponível em: https://doi.org/10.4000/champpenal.79. Acesso em: 12 jul. 2021.

HUGUES, E.C. Le regard sociologique: essais choisis (textes rassemblés et presentés par Jean-Michel Chapoulie). Paris: Editions de L'EHHESS, 1996.

JAS, N., Pesticides et santé des travailleurs en France Questions anciennes, nouveaux enjeux.

Courrier de l'environnement, INRA, n. 59, oct. 2010

\footnotetext{
5 "Um campo é um sistema especifico de relações objetivas, que podem ser de aliança elou de conflito, de concorrência elou de cooperação entre posições diferenciadas, socialmente definidas $e$ institucionalizadas independentes da existência física dos agentes que as ocupam" (ACCARDO, 1983, p. 30).
} 
GONZALEZ-LAPORTE, G. Recherche-action participative, collaborative, intervention, quelles explicitations. [Rapport de recherche] Labex ITEM. 2014. Disponível em: http://hal.univ-grenoble-alpes.fr/hal-01022115. Acesso em: 13 jul. 2021.

LAPASSADE, G. De l'ethnografie de l'école à la nouvelle recherche-action. Paris: Université de Paris VIII, 1993.

THIOLLENT, M. Metodologia da pesquisa-ação. São Paulo: Cortez e Autores Associados, 1986.

TRIPP, D. Pesquisa-ação: uma introdução metodológica. Educação e Pesquisa, São Paulo, V. 31. n.3. p. 443-466. set/dez. 2005.

PASSERON, J. C. Le raisonnement sociologique. Paris: Albin Michel Littérature, 2006.

SOULË, B. Observation participante ou participation observante? Usages et justifications de la notion participation observante en sciences sociales. Recherches Qualitatives, Vol. 27(1), 2007, p. 127-140. 